\title{
Notes on the vocalizations of Hume's Leaf-warbler (Phylloscopus humei)
}

Peter Boesman

In the following we briefly analyze and compare voice of the two races of Hume's Leaf-warbler (Phylloscopus humei). We also try to quantify the extent of any vocal differences using the criteria proposed by Tobias et al. (2010), as a support for taxonomic review. We have made use of sound recordings available on-line from Xeno Canto (XC).

Both taxa apparently have two song types:

$\underline{\text { humei }}$

song type 1
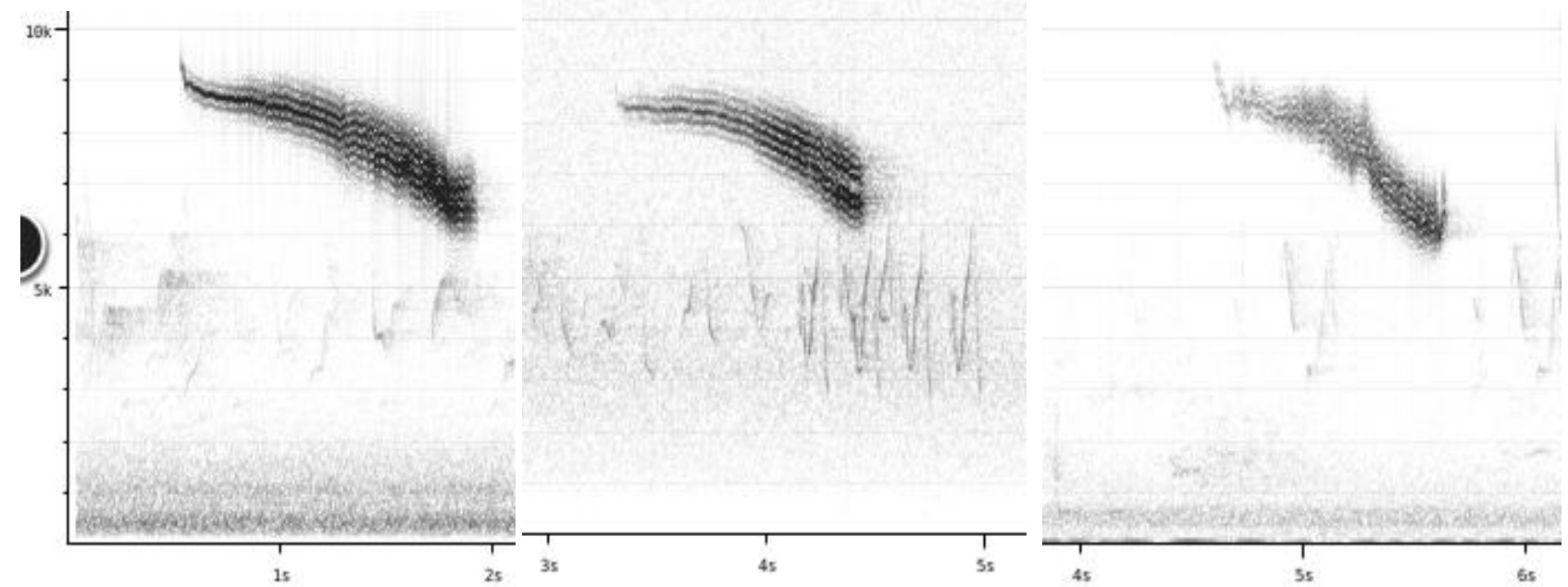

song type 2

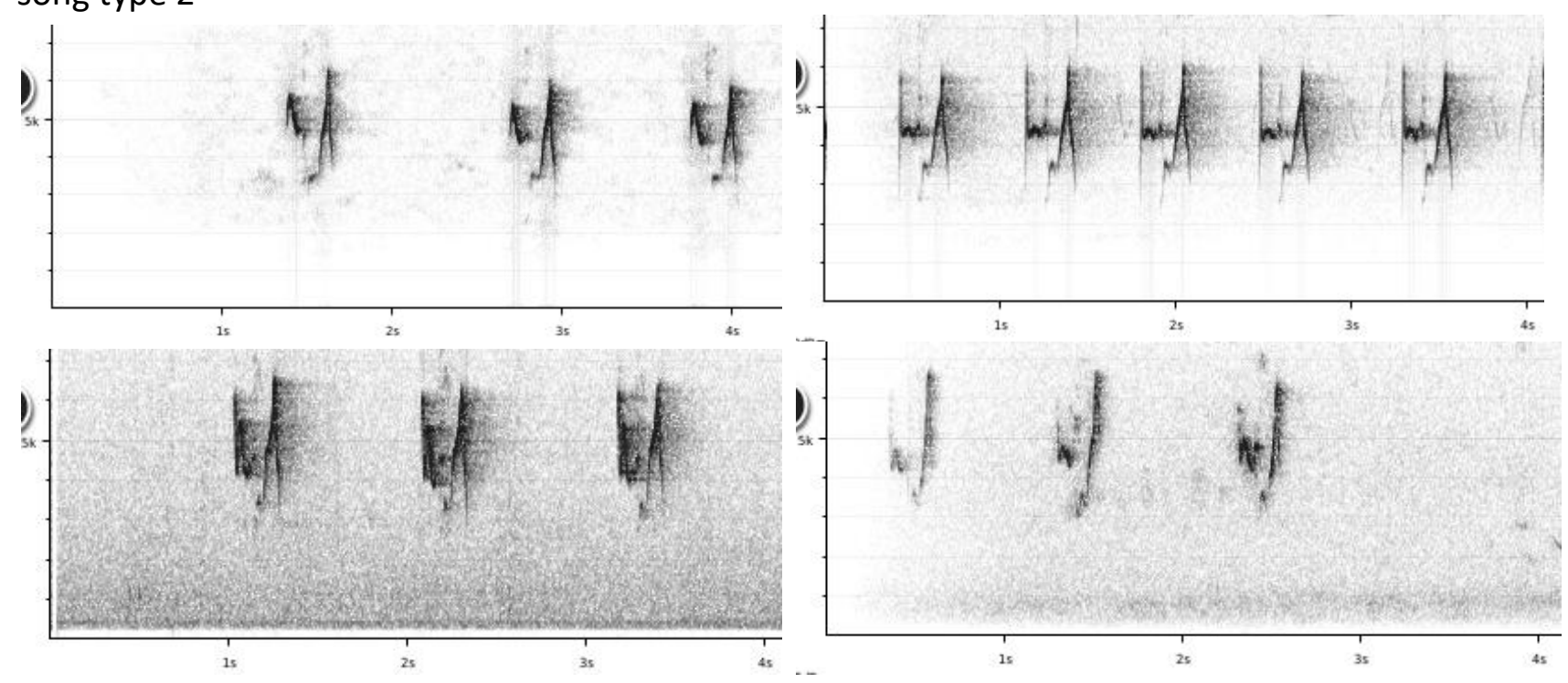




\section{HANDBOOK OF THE \\ BIRDSPF THE WORLD}
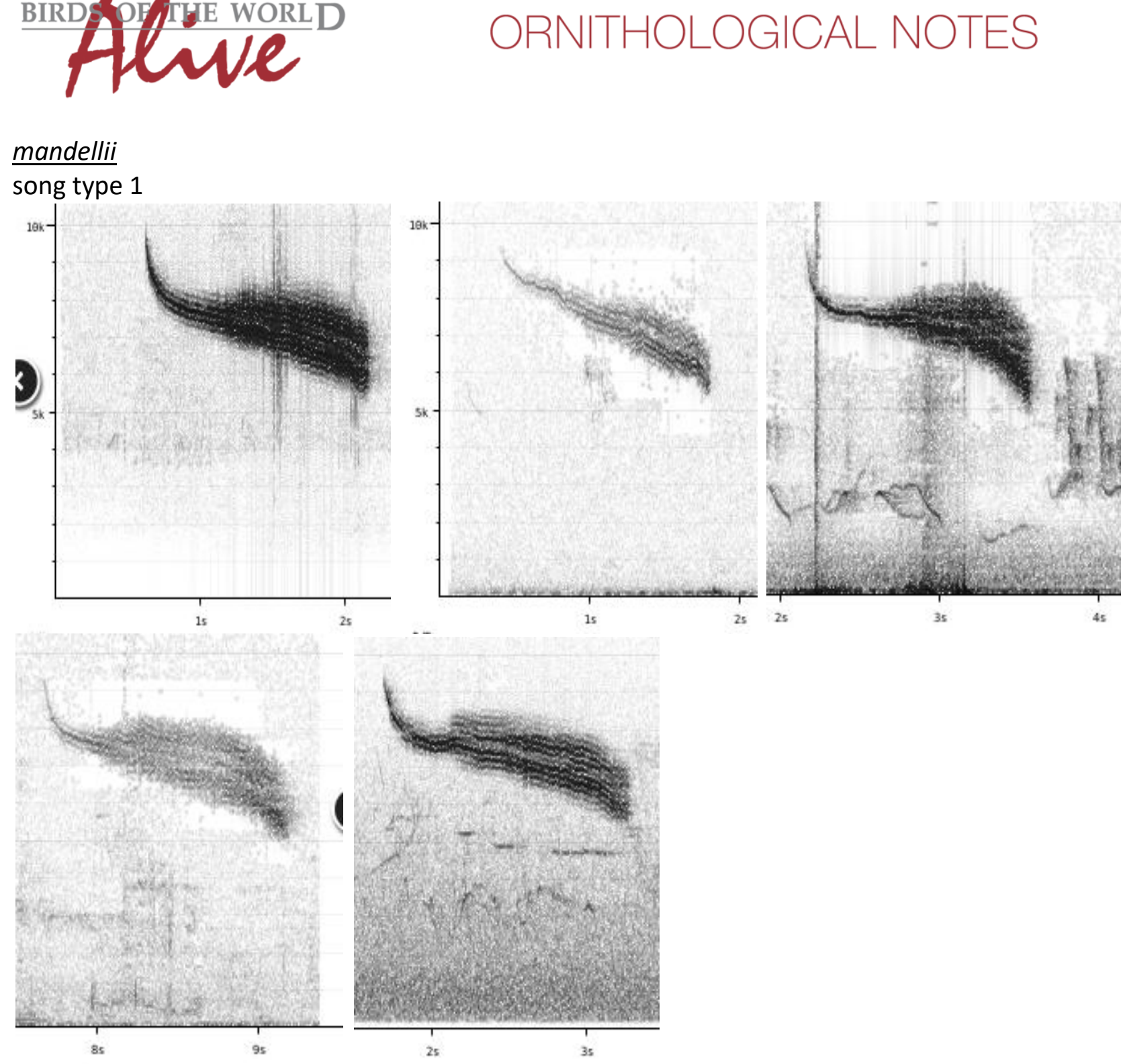

song type 2
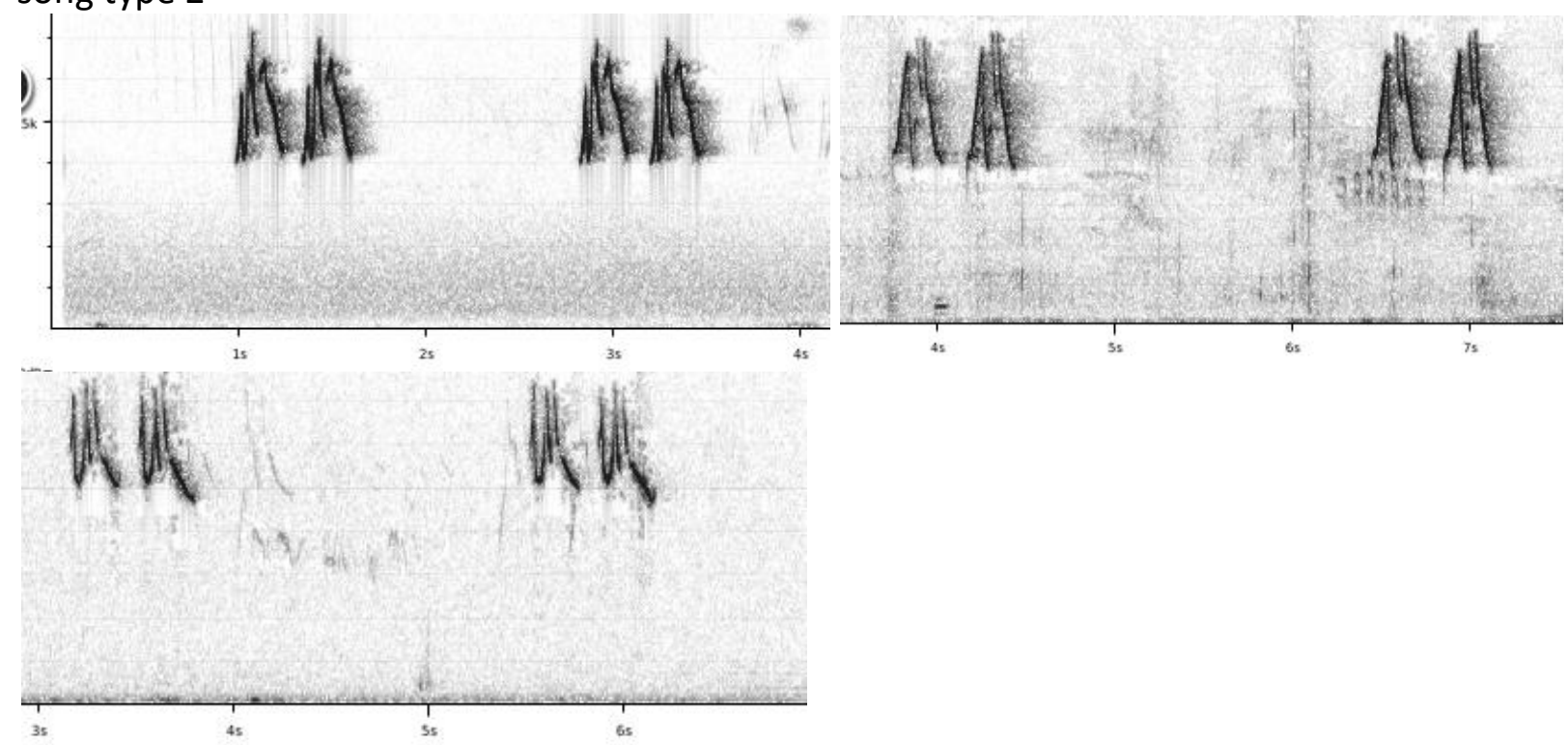


\section{HANDBOOK OF THE \\ BIRDSPFGE WORLD}

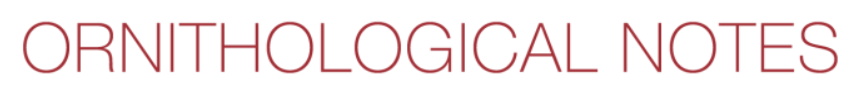

And both taxa also have a typical single or double call note:

\section{humei}

call types
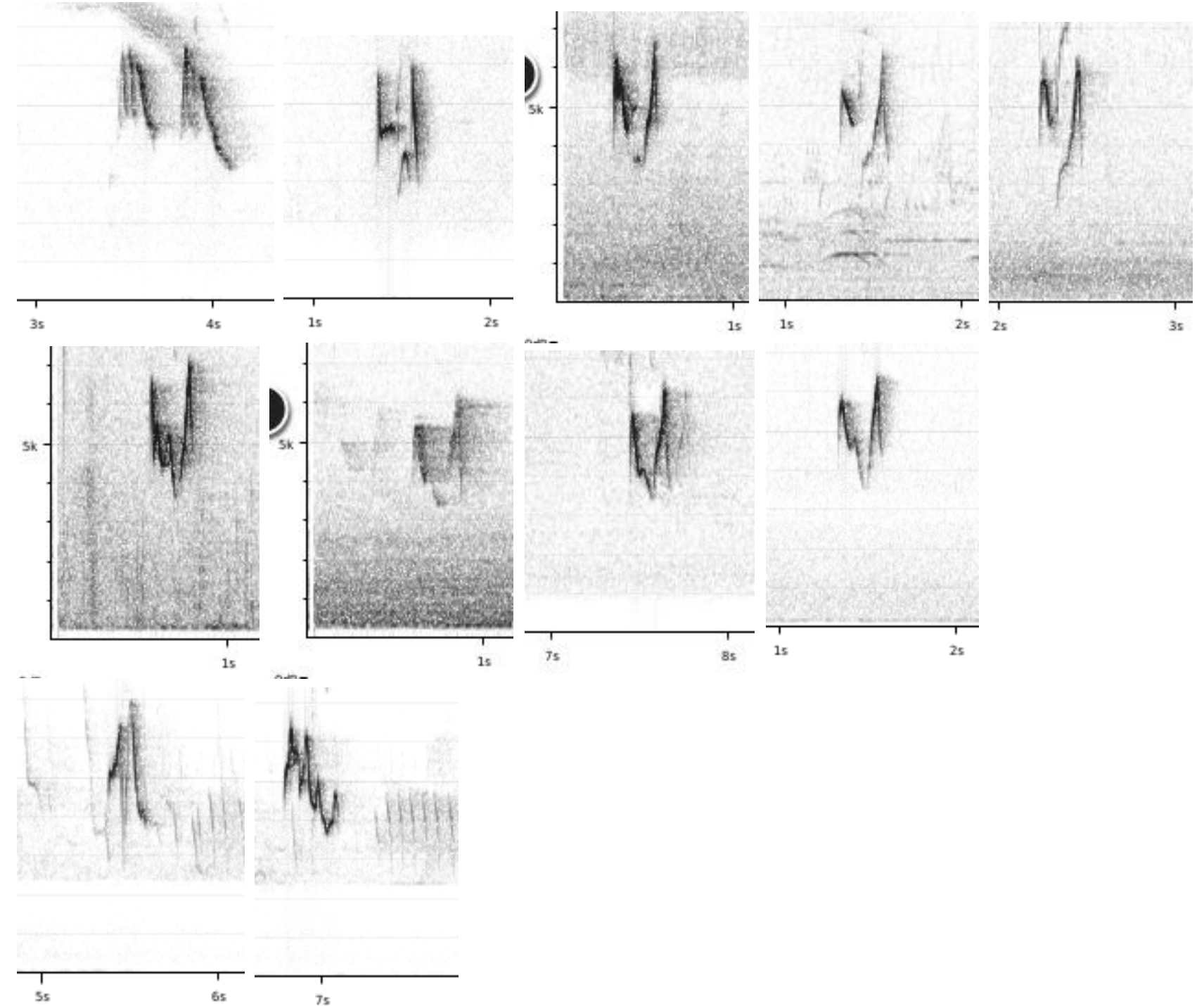

\section{mandellii}

call types
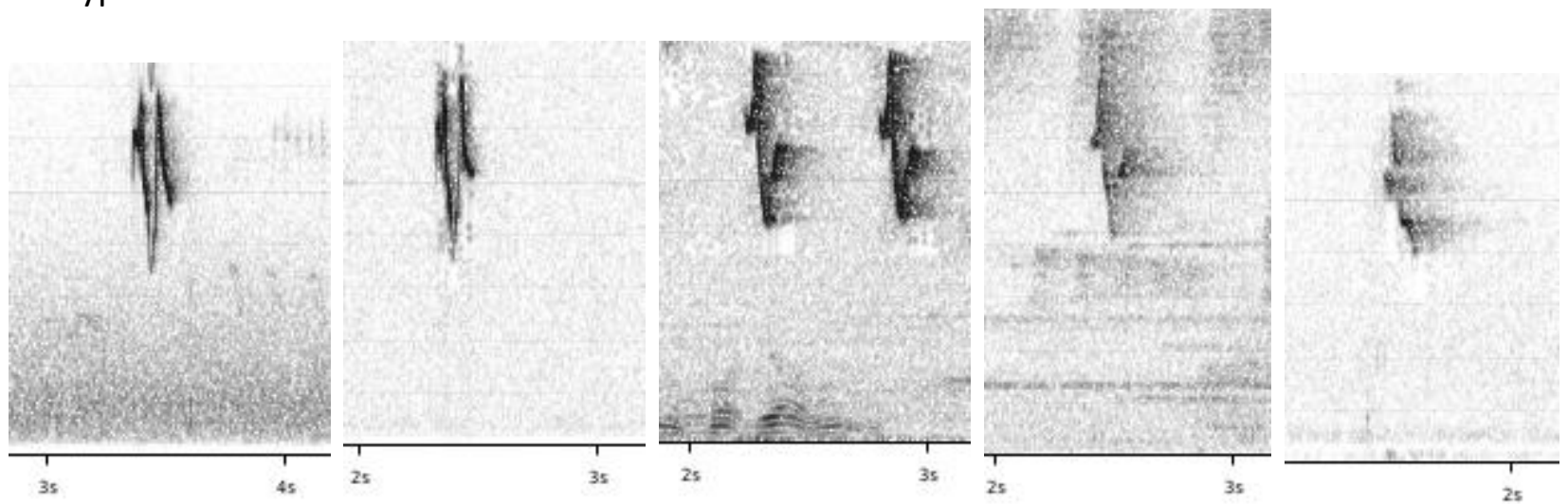

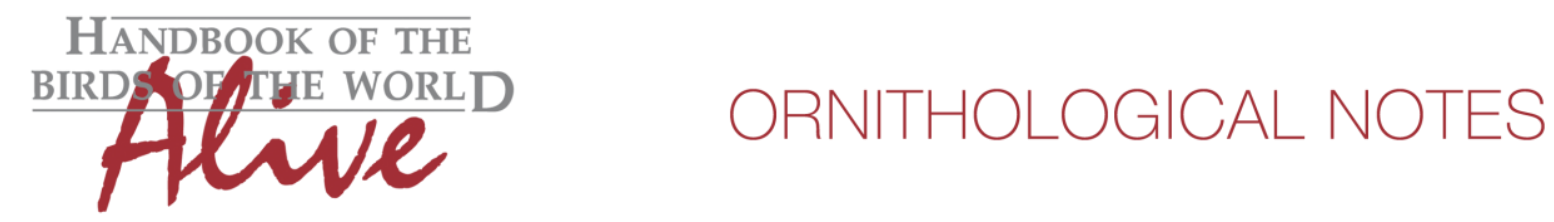

Structurally, voice of both races is very similar. In all homologous vocalizations there are however subtle differences:

Song type 1: mandelli drops much more in pitch at start (score 2) and frequency range of the buzzy part is wider (score 1-2)

Song type 2: while there may be some confusion about what is song and what is a repeated call, it would seem that the vocalization given in spring on the breeding grounds differs quite a bit (shapes easily told apart and typically doubled in mandellii) -> score about $1+2$

Call notes: differences here are equally subtle given the range of variation, and actually $P$. inornatus (which has a very different song) also comes close with certain calls. It would seem however that mandellli has a lot of calls very short in duration, while humei has slightly longer call notes which are often actually two separated notes or elements -> score about 2 based on duration.

All in all, it is clear there are consistent and fairly significant vocal differences between these two taxa. Vocal difference (especially of song) is however much less outspoken than in comparison with P. inornatus.

This note was finalized on 24th February 2016, using sound recordings available on-line at that moment. We would like to thank in particular the many sound recordists who placed their recordings for this species on XC.

\section{References}

Tobias, J.A., Seddon, N., Spottiswoode, C.N., Pilgrim, J.D., Fishpool, L.D.C. \& Collar, N.J. (2010). Quantitative criteria for species delimitation. Ibis 152(4): 724-746.

\section{Recommended citation}

Boesman, P. (2016). Notes on the vocalizations of Hume's Leaf-warbler (Phylloscopus humei). HBW Alive Ornithological Note 247. In: Handbook of the Birds of the World Alive. Lynx Edicions, Barcelona. (retrieved from http://www.hbw.com/node/932244 on 30 September 2016). 